\title{
The development of a neonatal communication intervention tool
}

\author{
Esedra Strasheim \\ Alta Kritzinger \\ Department of Communication Pathology, University of Pretoria
}

Brenda Louw

Department of Audiology and Speech-Language Pathology, East Tennessee State University

Correspondence to: E Strasheim (esedra1@gmail.com)

\begin{abstract}
Neonatal communication intervention is important in South Africa, which has an increased prevalence of infants born with risks for disabilities and where the majority of infants live in poverty. Local literature showed a dearth of information on the current service delivery and roles of speech-language therapists (SLTs) and audiologists in neonatal nurseries in the South African context. SLTs have the opportunity to provide the earliest intervention, provided that intervention is well-timed in the neonatal nursery context. The aim of the research was to compile a locally relevant neonatal communication intervention instrument/tool for use by SLTs in neonatal nurseries of public hospitals. The study entailed descriptive, exploratory research. During phase 1, a survey was received from 39 SLTs and 2 audiologists in six provinces. The data revealed that participants performed different roles in neonatal nurseries, which depended on the environment, tools, materials and instrumentation available to them. Many participants were inexperienced, but resourceful in their attempts to adapt tools/materials. Participants expressed needs for culturally appropriate and user-friendly instruments for parent guidance and staff/team training on the topic of developmental care. During phase 2, a tool for parent guidance titled Neonatal communication intervention programme for parents was compiled in English and isiZulu. The programme was piloted by three participants. Suggestions for enhancements of the programme were made, such as providing a glossary of terms, adapting the programme's language and terminology, and providing more illustrations. SLTs and audiologists must contribute to neonatal care of high-risk infants to facilitate development and to support families.
\end{abstract}

Keywords: developmental care, early communication intervention, neonatal communication intervention, neonatal nursery, public health context

Comprehensive management in the neonatal nursery includes not only medical treatment of the infant but also developmental care and the provision of guidance, counselling and information to the family who are part of the decision-making process regarding the infant's care (ASHA, 2005). A programme that has shown positive results for premature infants is the Newborn Individual Developmental Care and Assessment Programme (NIDCAP) (Als et al., 2004). This programme requires specialised training based in the USA, which makes it inaccessible to most South African professionals. Kangaroo mother care (KMC) has been shown to be a safe alternative for ThirdWorld countries, where $96 \%$ of the world's premature infants are born (Bergman, Linley \& Fawcus, 2004). The effectiveness and safety of KMC is well established (Bergman, Malan \& Hann, 2003) and it is regarded as an important developmental care practice for developing, as well as developed, contexts (Bergman et al., 2004).

In South Africa's public health sector, early communication intervention (ECI) services to neonates are less developed and less comprehensive in comparison with those of a developed country such as the USA (Kritzinger, Louw \& Hugo, 1995). While the role of the speech-language therapist (SLT) in the neonatal intensive care unit (NICU) is clearly described in international literature (ASHA, 2005; Rossetti, 2001; Ziev, 1999), currently no guidelines for service delivery in the NICU in the South African context exist (De Beer, 2003).

SLTs who are employed in South African provincial hospitals are often faced with difficult working conditions, such as lack of community awareness of services, inadequate instrumentation and tools, insufficient services of trained interpreters and limited literacy of caregivers (Fair \& Louw, 1999). The diversity of language and culture in South Africa poses a challenge for SLTs in providing family-centred early intervention services (Louw \& Avenant, 2002).

Current health care policies in South Africa prioritise care of mothers and young children, as can be seen in legislation that emphasises the provision of free primary health care to children under the age of 6 years (National Health Act, 2003). Although ECI may be regarded as a component of services to women and young children, it is still not a health care priority in South Africa. The undervalued perception of ECI is not only due to the HIV/AIDS pandemic, but also to the limited knowledge about the benefits of ECI, a shortage of ECI facilities and early communication interventionists, an insufficient referral system and poor teamwork (Kritzinger, 2000).

In a study conducted by H. Louw (2007) regarding ECI service delivery in public hospitals in four provinces in South Africa, it was concluded that some of the high-risk infants and families were still not receiving linguistically appropriate services. A shortage of qualified and trained interpreters was also identified (H. Louw, 2007), which presents an obstacle to effective ECI service delivery in public hospitals. South Africa has 11 official languages, of which isiZulu is the most commonly spoken (24\%) with English in 5th place (8\%) (Population Census Key Results, 2001); English is the language most commonly spoken by SLTs. Language differences may pose a considerable barrier to effective understanding between professionals and families (Madding, 2000). H. Louw (2007) found that only $11 \%$ of the respondents in her study worked with trained interpreters at their hospitals. Since the multilingual nature of the South African population creates barriers to service delivery, it necessitates different approaches to intervention.

The shortage of SLTs who can provide ECI and initiate prevention campaigns (Fair \& Louw, 1999) and the insufficient number of therapists in the public hospital context result in large caseloads. Another challenge to ECI in South Africa is a dearth of apparatus and materials for the assessment and treatment of high-risk and at-risk infants. H. Louw's findings (2007) indicated that $93 \%$ of community service SLTs employed in Mpumalanga, Western Cape, KwaZulu-Natal and Gauteng in the public health sector expressed the need for more culturally and language-appropriate materials specifically designed to address the unique needs of the South African community. The results 
confirm the earlier findings of Kritzinger et al. (1995) that there are limited diagnostic tools developed from a speech-language pathology and audiology perspective for neonatal assessment and management.

In South Africa, poverty is a characteristic of the majority of the neonatal population requiring ECI. Poverty in itself may not be the direct cause of developmental problems in young children, but family conditions such as malnutrition, inadequate prenatal care, exposure to infectious diseases and toxicants in utero, unsafe living conditions, living with parents who are addicted to alcohol or drugs and inadequate educational opportunities are all common in circumstances of poverty (Thompson, 1992). Certain risk conditions associated with communication disorders, such as low birth weight, cerebral palsy, fetal alcohol spectrum disorder and HIV/AIDS, also have a higher prevalence in South Africa than in developed countries (Kritzinger, 2000; Swanepoel, 2004). The high prevalence of conditions affecting young children is of significance to SLTs, as these conditions can be related to many developmental disorders but more specifically to communication delays and disorders (Kritzinger, 2000; Rossetti, 2001).

ASHA (2004) states that SLTs have the responsibility to fulfil ECI roles using practices that are based on research, family-centred, culturally and linguistically appropriate, developmentally appropriate and collaborative. The execution of these responsibilities and functions is dependent upon a well-developed theoretical and clinical foundation. Evidence-based practice is a framework for clinical decision making that entails the integration of best research evidence with clinical expertise and patient values (Johnson, 2006). According to Louw (2007), basing clinical decisions on scientific research is fundamental to ethical practice in ECI. In order to fulfil the roles and responsibilities in neonatal communication intervention effectively, the SLT requires certain tools. Local research already provides guidelines to useful training strategies. Gani (2004) found materials based on the Hanen programme (Pepper \& Weitzman, 2004) to be useful in training a group of caregivers in communication stimulation in a care centre, and a positive effect on caregiver-child interaction patterns was determined.

Best practice in developmental care in neonatal nurseries needs to be encouraged and facilitated, which necessitates the development of appropriate tools for the local context. ASHA (2005) urges speechlanguage pathologists to develop culturally appropriate programmes that meet the needs of ethnically and linguistically diverse families. Culturally and contextually appropriate tools and programmes for neonatal communication intervention therefore need to be developed for the South African context, in order to serve the unique high-risk population in South Africa in an effective and ethical manner.

The unique contextual reality of South Africa should be taken into account. To be contextually relevant, tools should be based upon an expressed need within a given context. If based on Western models of communication stimulation, these tools should be adapted appropriately for the South African context. Because of the diversity of cultural groups in South Africa, overseas tools and programmes cannot merely be translated (Visser, 2005). The interdependent relationship between culture and language must be carefully considered during cross-cultural service delivery, otherwise the tool will still not be suitable even once translated (Pakendorf, 1998). It may also be beneficial to consider other adaptations in order to bridge additional challenges such as limited literacy among caregivers. According to Louw, Shibambu and Roemer (2006), literacy issues may be overcome by using visual sources such as pictorial illustrations and demonstrations, as written materials are not necessarily viewed as important, especially by individuals with low literacy levels.

To propose a solution to address the dearth of tools in the public health context, a survey was conducted to determine the perceptions of SLTs and audiologists providing services in provincial hospitals in South Africa. The aim of the survey was to investigate the role of SLTs in the neonatal nurseries and to identify participants' needs in terms of neonatal communication intervention instruments/tools. This information was utilised to compile a preliminary instrument/tool based on the selection of one of the perceived needs of the participants.

\section{Method}

\section{Aim}

The overall aim of this study was to compile a locally relevant neonatal communication intervention instrument/tool for use by SLTs in the neonatal nurseries of public hospitals.

The following objectives were formulated in order to reach the main aim:

- to describe the perceptions of SLTs and audiologists providing ECI services in provincial hospitals in South Africa regarding their role in the neonatal nurseries

- to identify participants' needs in terms of neonatal communication intervention instruments/tools

- to select and justify a specific need of the participants in terms of neonatal communication intervention instruments/tools in the public hospital context

- to compile a preliminary instrument/tool based on the selection of one of the perceived needs of the participants

- to pre-test the completed instrument/tool and make changes, if necessary.

\section{Research design}

For the purpose of this study a descriptive, exploratory study within the quantitative and qualitative frameworks of research design was selected.

\section{Ethical considerations}

Ethical clearance to conduct the study was obtained from the Research Ethics Committee of the Faculty of Humanities, University of Pretoria. All participants gave written informed consent. Data were treated with confidentiality and no identifying information of the participants or their hospitals was reported.

\section{Participants}

All the participants in this study had to provide ECI to infants in a neonatal nursery such as an NICU, a neonatal high-care ward or a KMC ward, as this study specifically focused on the participants' needs regarding neonatal communication intervention. Permission was obtained in writing from 6 of the 9 provinces contacted, namely Gauteng, KwaZulu-Natal, Eastern Cape, North West, Northern Cape and Mpumalanga. The Departments of Health of the Free State, Western Cape and Limpopo provinces did not respond within the time constraints of this study, which further reduced the population available for the research. The provincial health departments were requested to provide statistics regarding the number of SLTs and audiologists employed at the hospitals in their province, as well as to provide each hospital's contact details. The potential participants targeted for the study were contacted telephonically at the hospitals to explain the aim of the study and discuss participation. All participants who responded were included in the study.

Questionnaires were sent to 175 SLTs and audiologists in public hospitals in the six provinces. A total of 41 SLTs and audiologists returned a completed questionnaire, a return rate of $23 \%$. The responses obtained are therefore not representative of speech-language therapy and audiology services in the public health sector in South Africa. The majority of participants worked mostly at district or regional hospitals, as well as at community outreach clinics. They mostly provided ECI in neonatal high-care units and KMC units of their hospitals. Most participants appeared to be inexperienced in providing neonatal communication intervention services. They may have been without supervision, as most participants were the only SLTs/audiologists employed at their hospital and had limited access to interpreters and assistants. The participants' characteristics are displayed in Table I.

\section{Research process}

The research was conducted in two sequential phases. 


\section{Table I. Characteristics of the participants}

\begin{tabular}{|c|c|}
\hline \multirow[t]{3}{*}{ Professional qualifications } & SLT $-49 \%$ \\
\hline & SLT \& audiologist $-46 \%$ \\
\hline & Audiologist $-5 \%$ \\
\hline \multirow[t]{6}{*}{ Provinces where employed } & Eastern Cape - 5\% \\
\hline & Gauteng $-8 \%$ \\
\hline & KwaZulu-Natal - 25\% \\
\hline & Mpumalanga - 29\% \\
\hline & Northern Cape - $28 \%$ \\
\hline & North West - 5\% \\
\hline \multirow{4}{*}{$\begin{array}{l}\text { Years of experience in govern- } \\
\text { ment sector }\end{array}$} & 1 year or less -25 participants \\
\hline & 2 years -6 participants \\
\hline & 3 years -3 participants \\
\hline & 5 years or more -6 participants \\
\hline Contexts of service provision & $\begin{array}{l}\text { Clinics/community health centres } \\
-26 \text { participants }\end{array}$ \\
\hline \multirow[t]{3}{*}{$\begin{array}{l}\text { (participants indicated more than } \\
\text { one working context) }\end{array}$} & $\begin{array}{l}\text { District/regional hospital - } 30 \\
\text { participants }\end{array}$ \\
\hline & $\begin{array}{l}\text { Tertiary/academic hospital - } 12 \\
\text { participants }\end{array}$ \\
\hline & Other - 1 participant \\
\hline \multirow[t]{3}{*}{ Wards where EI was provided } & NICU - 14 participants \\
\hline & $\begin{array}{l}\text { Neonatal high-care unit - } 23 \\
\text { participants }\end{array}$ \\
\hline & $\begin{array}{l}\text { Kangaroo mother care ward - } 20 \\
\text { participants }\end{array}$ \\
\hline \multirow{4}{*}{$\begin{array}{l}\text { Number of SLPs and/or audiolo- } \\
\text { gists in the department }\end{array}$} & $1-15$ participants \\
\hline & $2-10$ participants \\
\hline & 3 - 5 participants \\
\hline & 4 or more -11 participants \\
\hline $\begin{array}{l}\text { Trained interpreters or assistants } \\
\text { at their disposal }\end{array}$ & $\begin{array}{l}\text { Yes }-10 \% \\
\text { No }-90 \%\end{array}$ \\
\hline
\end{tabular}

\section{Data collection: phase 1}

A self-designed questionnaire was selected as the data collection tool to conduct the survey. A pilot study was conducted to pre-test the questionnaire which provided recommendations to enhance its efficacy and practicality. The questionnaire was e-mailed or faxed to the potential participants during phase 1 of the study. The first section gathered biographical data, which was used to describe the participants and to interpret the data from other sections of the questionnaire. The following section enquired about the service delivery regarding ECI in the hospital, task allocations, contexts for ECI (NICU, neonatal high care, $\mathrm{KMC}$ ) and the participants' functions and roles in terms of assessment and intervention with the infant, parents or staff. The questionnaire enquired about the participants' needs in terms of service delivery, their perceptions of culturally appropriate and user-friendly tools, and their needs in terms of tools regarding assessment, intervention directed at the parents/caregivers and intervention directed at the staff/team.

\section{Data analysis: phase 1}

Frequency distribution was set up from the raw data to obtain an overall view of the data (Maxwell \& Satake, 2006). Descriptive statistics were used to examine the data and to graphically display the data (Maxwell \& Satake, 2006). The qualitative data were presented as detailed textual descriptions, and phase 1 included direct quotations from participants (Fossey, Harvey, McDermott \& Davidson, 2002).

\section{Method: phase 2}

The needs analysis in phase 1 informed the type and the format of the tool, which was compiled during phase 2 . The tool could therefore only be compiled after the results of phase 1 were obtained. For this reason, the instrument/tool was pre-tested in a pilot study as part of phase 2 and presented in the results. The evaluation of the training tool entailed descriptive data, which were analysed according to recurring themes.

\section{Validity}

In this study SLTs' and audiologists' perceptions of their roles, their competence, work satisfaction and their needs were constructs that could not be measured directly. The construct validity could therefore be influenced by the participants' subjective opinions and by the wording of questions in the questionnaire. The content of the questionnaire was reviewed by a statistician to determine whether the questions were relevant and appropriate for statistical purposes. The construct and content validity of the questionnaire were determined by making use of a pilot study, and certain changes were implemented according to the recommendations made.

Because of the small sample size, the results of this survey were not representative of the perceptions of all SLTs and audiologists employed in government hospitals. Therefore no attempt will be made to generalise the findings.

\section{Reliability}

The questionnaire was piloted to determine whether any items were misleading or unclear, which could result in participants misinterpreting some items. The pilot study therefore also contributed to the reliability of the questionnaire. The data collection procedures were described in detail, contributing to the repeatability of the study and thereby increasing its reliability.

\section{Results and discussion: Phase 1 \\ Participants' roles in the neonatal nursery}

Figure 1 illustrates that some participants performed roles in the NICU that require specialised equipment, such as hearing evaluation and video-fluoroscopy. Video-fluoroscopic instrumentation is not readily available at all hospitals and is usually only found in tertiary or academic hospitals because of the costs involved, which explains why few participants performed this role. This finding can be explained by the fact that most of the participants were employed at district or regional hospitals that would not have specialised equipment such as videofluoroscopy. Participants appeared to be performing multidimensional professional roles relating to screening and assessment, which is attributed to their awareness of the risks of development problems in the areas of attachment and communication development in infants with low birth weight and preterm birth.

The majority of the participants reported that they fulfil a number of roles in direct intervention with infants and parents, as seen in Figure 2. Most SLTs were the only SLT/audiologist employed in their department and had large caseloads, which possibly did not leave time to engage in discharge planning and planning of follow-up services.

Because patients come from a wide geographical area and have limited finances and transport to return to the hospital or clinic, regular followup services are a problem area in the South African public health sector (Fair \& Louw, 1999). Given the nature of the South African context, the roles performed by the participants need to be expanded and adapted to meet local needs to improve neonatal communication intervention service delivery.

According to Figure 3, most participants appeared to be aware of the impact they might have in this context through teamwork, as this is preferred practice because of the benefits for the infant, the family and the SLT. Early intervention in the NICU should follow a transdisciplinary team approach (Rossetti, 2001).

However, in-service training of staff members was not yet performed by all facilities, and their service delivery was limited by poor attendance of ward rounds. Ziev (1999) describes this function as an opportunity to learn from others and to become a familiar face among team 
members, as well as to request referrals based on infants' symptoms or histories. As mentioned earlier, many participants were the only SLT/ audiologist employed in their department, which may have limited the time available for them to attend neonatal ward rounds as they may have been involved in other paediatric or adult ward rounds, clinics or consultations. This is problematic as many participants had limited experience, which resulted in missed opportunities in the neonatal nursery.

Two of the participants in this study were qualified as audiologists only. Only one of the two audiologists performed hearing screenings, which is ascribed to the fact that hearing screening equipment is not readily available in government hospitals (Theunissen \& Swanepoel, 2008). Both audiologists worked as part of a team and consulted with other team members in accordance with ASHA's guidelines for audiologists (2008B). Current literature emphasises the importance of ongoing audiological and medical monitoring of any child who demonstrates risk indicators for delayed onset or progressive hearing loss for at least 3 years (Northern \& Downs, 2002). Interestingly, both audiologists also assisted in discharge planning and planning of follow-up treatment/

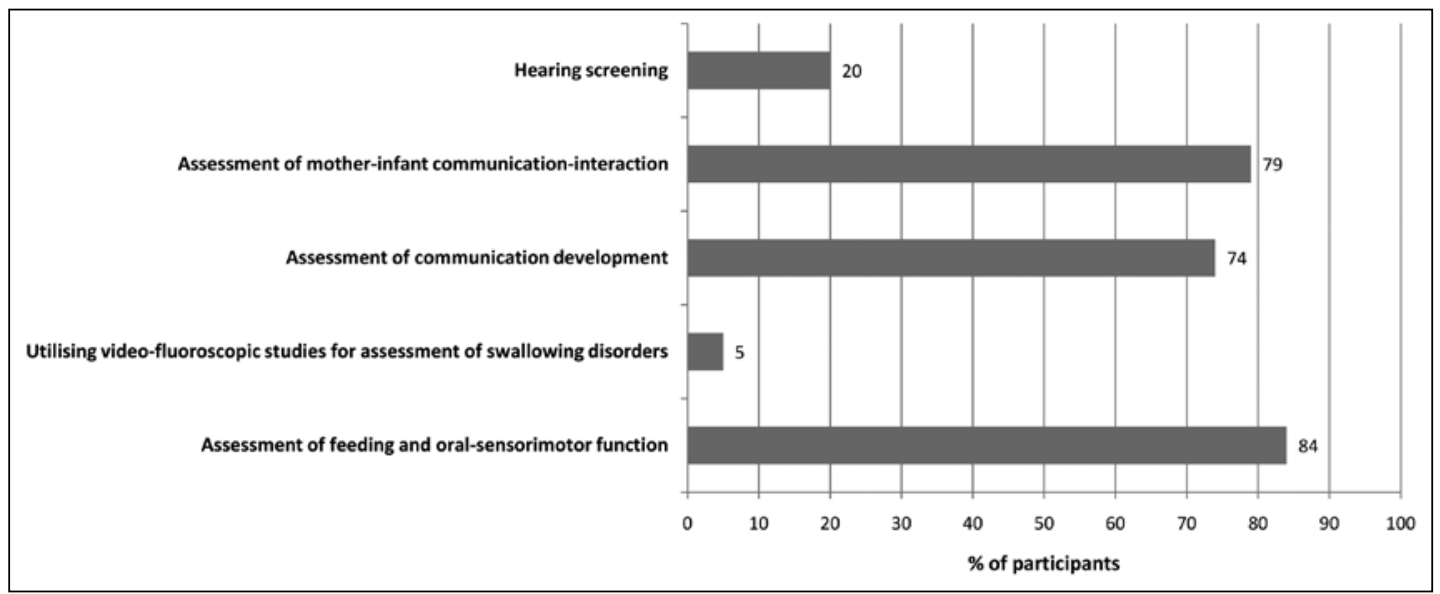

Fig. 1. Speech-language therapists' indication of their roles regarding screening and assessment of the high-risk infant ( $\mathrm{N}=39)$.

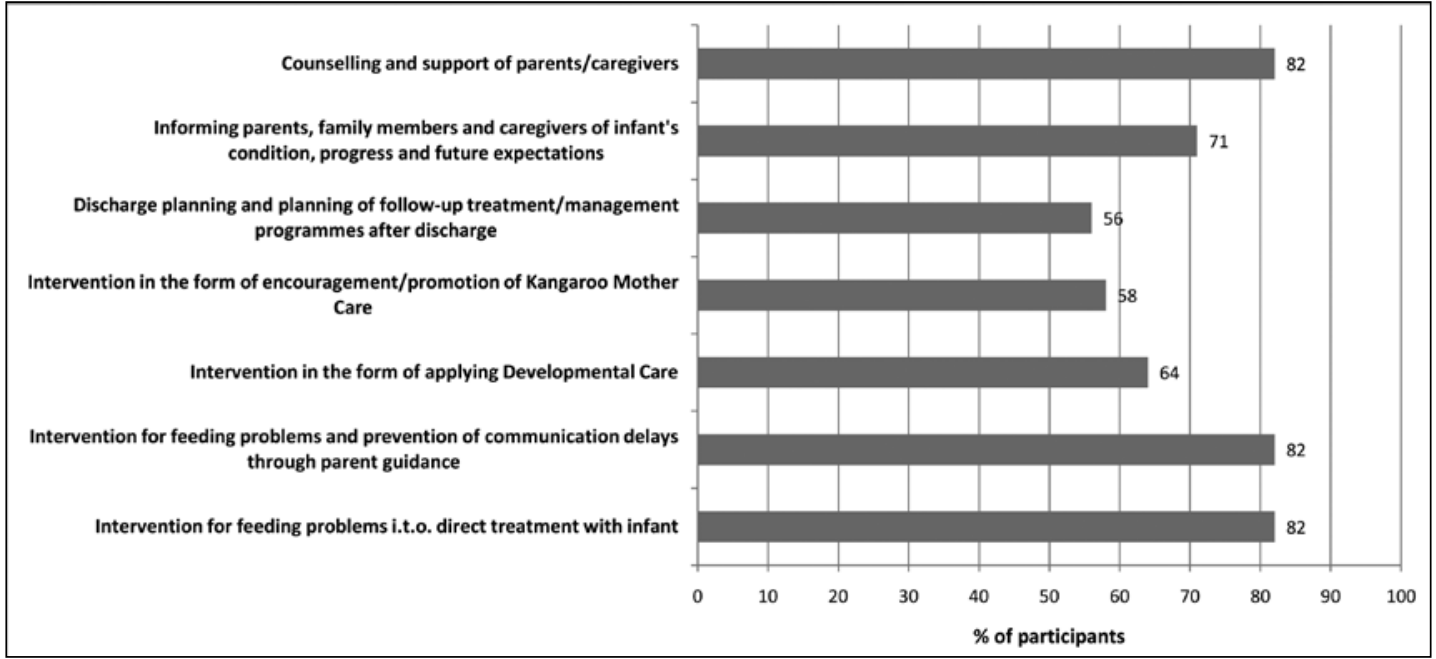

Fig. 2. Speech-language therapists' roles in intervention specifically directed at the infant and parents/caregivers $(\mathrm{N}=39)$.

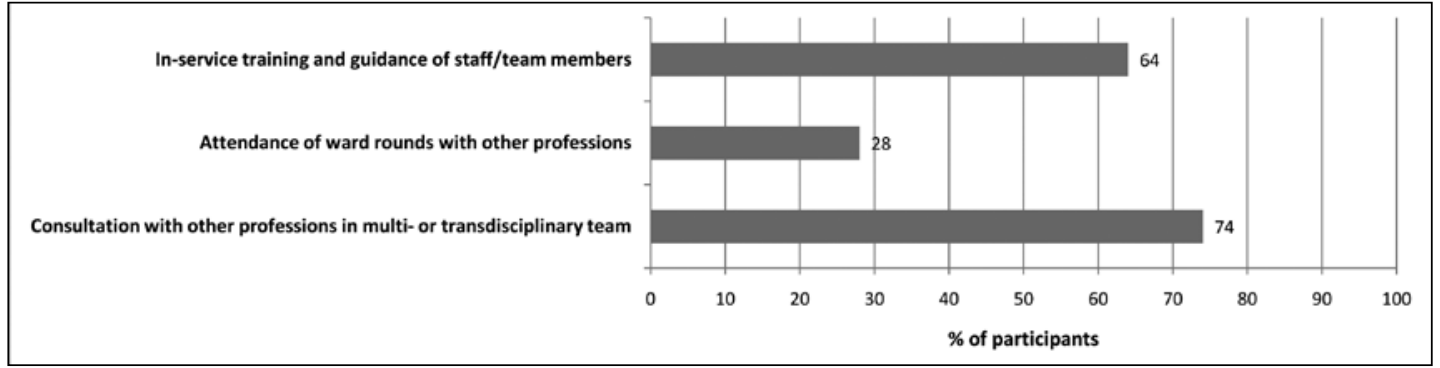

Fig. 3. Speech-language therapists' roles in intervention specifically directed at staff and team members ( $\mathrm{N}=39)$. management after discharge, while only half of the larger group of 39 SLT participants performed this role. This may be due to a lack of infant follow-up clinics at many district or regional hospitals. Families need information, consistent encouragement, reassurance, and positive feedback regarding their competency and ability to cope with the birth and hospitalisation of their critically ill newborn (Northern \& Downs, 2002).

\section{Participants' needs in the neonatal nursery}

An overview of the needs of the SLTs as determined in phase 1 was ine 5 most frequently indicated needs are highlighted, namely tools for parent guidance (4 topics), a tool for staff and team training (1 topic) and an assessment tool (1 topic) ( 2 needs in 4th place).

ECI services are required to be family-centred, as well as culturally linguistically responsive (ASHA, 2008A). Neonatal communication intervention services therefore cannot be effective without culturally appropriate tools. An urgent need for culturally appropriate materials for use in the neonatal nurseries of provincial hospitals was identified. Participants were aware of the importance of providing culturally sensitive services, but were hampered by the dearth of tools and materials that could be utilised in clinical practice.

Phase 1 demonstrated that participants performed different roles in neonatal nurseries, which were determined by the environment, tools, materials and instrumentation available to them. Although many participants were relatively inexperienced, they were resourceful in their attempts to develop and adapt tools and materials. The fact that these self-developed and adapted tools are not research-based compromises the quality of services and precludes best practice. The participants expressed a need for culturally appropriate and user-friendly instruments specifically for parent guidance and staff/team training. These descriptive findings justified the compilation and development of a locally relevant instrument/tool for use in public hospitals' neonatal nurseries.

Results and discussion: phase 2 The compilation of a neonatal communication intervention tool

A tool regarding parent guidance with the topic of developmental care was selected as the tool to be compiled, as this was a need 
Table II. Speech-language therapists' needs $(N=39)$

\begin{tabular}{|c|c|c|c|c|c|}
\hline & Need & $\begin{array}{l}\text { No. of responses } \\
\qquad(N=39)\end{array}$ & $\begin{array}{l}\text { No. who indi- } \\
\text { cated need }\end{array}$ & $\%$ & $\begin{array}{c}\text { Hierarchy } \\
1 \text { - } 14\end{array}$ \\
\hline \multirow[t]{4}{*}{ Assessment tools } & Neonate's communication development & 36 & 15 & 41.6 & 9 \\
\hline & Feeding & 34 & 15 & 44.1 & 8 \\
\hline & Mother-child communication-interaction & 33 & 16 & 48.4 & 7 \\
\hline & Neonatal nursery environment & 33 & 19 & 57.5 & 3 \\
\hline \multirow[t]{8}{*}{ Parent guidance tools } & Neonatal nursery environment and staff & 36 & 24 & 66.6 & 1 \\
\hline & Paediatric dysphagia and feeding therapy & 34 & 18 & 52.9 & 5 \\
\hline & Over-stimulation, identifying infant's stress cues & 35 & 19 & 54.2 & 4 \\
\hline & Developmental care & 35 & 19 & 54.2 & 4 \\
\hline & Kangaroo mother care (KMC) & 35 & 8 & 22.8 & 14 \\
\hline & Communication interaction with infant & 35 & 12 & 34.2 & 11 \\
\hline & Developmental milestones and follow-up after discharge & 34 & 9 & 26.4 & 12 \\
\hline & Normal communication development & 36 & 9 & 25.0 & 13 \\
\hline \multirow[t]{3}{*}{ Staff/team training tools } & Developmental care & 36 & 23 & 63.8 & 2 \\
\hline & KMC \& ECI & 35 & 13 & 37.1 & 10 \\
\hline & Role of the SLT in the neonatal nursery & 36 & 19 & 52.7 & 6 \\
\hline
\end{tabular}

Highlighted sections indicate the most frequently mentioned needs.

indicated by the majority of the SLT participants. Most participants were also involved in services directed at parents/caregivers in the neonatal nursery. The 'Neonatal communication intervention programme for parents' aimed to provide SLTs in local public hospitals with a programme to educate and guide parents/caregivers of infants in the neonatal nursery regarding developmental care, early reciprocal interaction and appropriate stimulation of their infants. Adult-learning principles were utilised in the compilation of the programme. Guidelines to teach adult learners consider mature learners as independent and self-directed (Kaufman, 2003).

The researcher formulated an aim as well as outcomes for the programme (Popich, 2003). The structure and sequence of the programme as conceptualised is illustrated in Figure 4. The programme is divided into four sections, which include an introduction with 'warm-up time' and definitions, information on the behaviours of the neonate, information on how parents may respond to these behaviours, and a conclusion that informs parents of options for follow-up services and provides time for reflection and questions. Informal terminology was used to make the language more accessible to the parents/caregivers. The term 'baby' is used in the programme instead of 'infant' as this is the term most commonly used by South African parents in conversation (Popich, 2003).

It was decided that the programme should consist of a Microsoft PowerPoint presentation and a handout for parents. The PowerPoint presentation was provided in two different formats as it allows each clinician to select a method that is conducive to his/her working environment. Some SLTs and audiologists in public hospitals have limited technical resources, and the PowerPoint presentation was therefore provided on a compact disc as well as transparencies. Handouts were provided to parents during the programme to generalise and reinforce the newly learnt information as well as to actively involve each parent during the presentation. The handout included photos and images to manage literacy barriers. The content of the handout was translated into isiZulu by a private translation service to address language barriers. IsiZulu was selected as it is the home language of almost a quarter of South Africans and is the language most spoken in South Africa (Population Census Key Results, 2001).

The programme was pre-tested in a pilot study, which concluded that the programme was enjoyed by the parents who received the training.

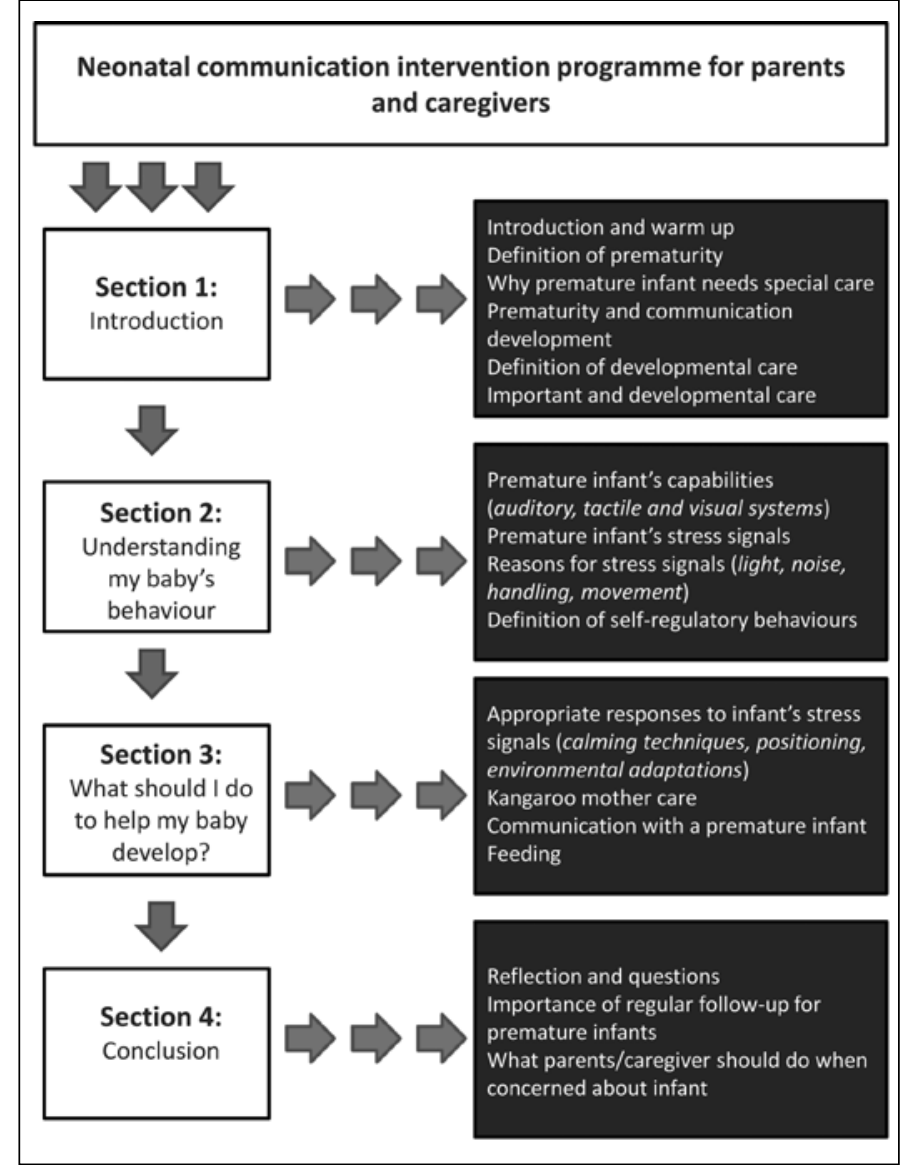

Fig. 4. Structure and content of the programme.

It was further determined that the content was appropriate but that the programme should be more concise and shorter so as to be more user-friendly. The parent handout was deemed suitable for the training. Certain suggestions for enhancements of the programme were made during the pilot study, such as providing a glossary of terms with definitions for therapists to use and adapting the programme's language and terminology. 


\section{Clinical and theoretical implications}

The current research identified and attempted to fulfil a need expressed by SLTs and audiologists. The study managed to achieve the aim of compiling a programme for SLTs for use with parents and caregivers in the neonatal nurseries in South African provincial hospitals. This study highlighted the role of the SLT and audiologist in terms of prevention of communication delays and disorders. This research is an example for SLTs and audiologists in the public health sector on how to use adult education principles in parent training to prevent communication delays and disorders in infants. The programme could also be used for raising awareness of ECI services within a certain community. South Africa has an increased prevalence of infants at risk for communication disorders (Kritzinger, 2000), and marketing of ECI among the general public, as well as health care workers, should therefore be a priority of local SLTs working in the public health sector. According to ASHA (2008a) ECI services must promote children's participation in natural environments, which include community settings outside the home environment, where children without disabilities participate. Community work increases the existing professional knowledge on diverse communities within South Africa, which presents therapists with the opportunity to implement prevention programmes such as adult training (Popich, 2003). This study emphasised involvement in community work and not only in the lives of individual families. The research could be used as an example of caregiver training within a specific community in order to reach more infants and toddlers in need of ECI services and to improve the current services in communities. This study highlighted information on the roles of SLTs and audiologists in the neonatal care of high-risk infants in the public health sector. This research gathered valuable information regarding the roles and responsibilities of SLTs and audiologists in local NICU, neonatal high-care and KMC nurseries. It can therefore be used to guide future attempts to compile local guidelines for SLTs in the NICU.

\section{Conclusion}

The study complied with the guiding principles for best practice in ECI (ASHA, 2008a) as it aims to be family-centred, culturally and linguistically responsive and developmentally supportive, to promote children's participation in their natural environments, to be comprehensive, co-ordinated and team-based, and is based on evidence. This research therefore contributed to neonatal care of highrisk infants in South Africa.

The increased prevalence of infants at risk for communication disorders in South Africa (Kritzinger, 2000) necessitates early interventionists to become involved in clinical and research efforts to develop ECI services for provincial hospitals. SLTs and audiologists not only have an essential role to fulfil in the neonatal nursery, but also have an ethical responsibility to develop creative solutions for challenges arising from service delivery in the South African public health context. SLTs and audiologists must contribute to neonatal care of high-risk infants to facilitate their optimal development.

Acknowledgements. The authors would like to thank the professionals who participated in this study and who are committed to early communication intervention.

The corresponding author (esedra1@gmail.com) may be contacted for more information about obtaining the Neonatal communication intervention programme for parents'.
Authors' note. Since the article was accepted for publication, SASLHA has adopted revised guidelines for early communication intervention, which include specific guidelines on neonatal communication intervention. The document may be obtained from the Ethics and Standards Committee (2011). Guidelines: Early Communication Intervention. www.saslha.co.za

\section{References}

Als, H., Duffy, F.H., McAnulty, G., Rivkin, M.J., Vajapeyam, S., Mulkern, R.V., Warfield, S.K., Huppi, P.S., Butler, S.C., Conneman, N., Fischer, C., \& Eichenwald, E.C. (2004). Early experience alters brain function and structure. Pediatrics, 113, 846-857.

American Speech-Language Hearing Association (2004). Roles and Responsibilities of Speech-Language Pathologists in the Neonatal Intensive Care Unit: Position Statement. Retrieved on 24 April 2006 from www.asha.org

American Speech-Language Hearing Association (2005). Roles and responsibilities of speech-language pathologists in the neonatal intensive care unit: Guidelines. Retrieved on 24 April 2006 from http:// www.asha.org

American Speech-Language Hearing Association (2008a). Roles and Responsibilities of Speech-Language Pathologists in Early Intervention: Guidelines. Retrieved on 27 August 2008 from http://www.asha.org American Speech-Language Hearing Association. (2008b). Scope of practice in audiology. Retrieved on 27 August 2008 from http://www.asha.org

Bergman, N.J., Linley, L.L., \& Fawcus, S.R. (2004). Randomized controlled trial of skin-to-skin contact from birth versus conventional incubator for physiological stabilization in $1200-2199$ gram newborns. Acta Paediatrica, 93, 779-785.

Bergman, N.J., Malan, A., \& Hann, M. (2003). News from the Regions - South Africa. Fourth International Workshop on Kangaroo Mother Care. Journal of Tropical Pediatrics, 49(5), 311-312.

De Beer, M. (2003). Die rol van 'n groep spraak-taalterapeute in neonatale hoësorgeenhede, Unpublished B. Communication Pathology research project, University of Pretoria.

Fair, L., \& Louw, B. (1999). Early communication intervention within a community-based intervention model in South Africa. The South African Journal of Communication Disorders, 46, 13-23.

Fossey, E., Harvey, C., McDermott, F., \& Davidson, L. (2002). Understanding and evaluating qualitative research. Australian and New Zealand Journal of Psychiatry, 36, 717-732.

Gani, A. (2004). Caregivers of infants and young children with paediatric HIV/AIDS in a care centre: Impact of a training programme on caregiver-child-interaction patterns. Unpublished B. centre: Impact of a training programme on caregiver-child-inter
Communication Pathology research report, University of Pretoria.

Johnson, C. (2006). Getting started in evidence-based practice for childhood speech-language disorders. American Journal of Speech-Language Pathology, 15, 20-35.

Kaufman, D.M. (2003). ABC of learning and teaching in medicine: Applying educational theory in practice. $B M J, 326,213-216$.

Kritzinger, A.M. (2000). Establishing a computer-based data system for early communication intervention in South Africa. Unpublished D.Phil. thesis, Faculty of Humanities, University of Pretoria.

Kritzinger, A., Louw, B., \& Hugo, R. (1995). Communication skills of biologically at-risk neonates. South African Journal of Communication Disorders, 42, 7-17.

Louw, B. (2007). Introduction to evidence-based practice in early communication intervention. PowerPoint Presentation at seminar on Evidence Based Practice in Early Communication Intervention, Department of Communication Pathology, University of Pretoria, August 2007.

Louw, B., \& Avenant, C. (2002). Culture as a context for intervention: Developing a culturally congruent early intervention programme. International Paediatrics, 17(3), 145-150.

Louw, B., Shibambu, M., \& Roemer, K. (2006). Facilitating cleft palate team participation of culturally diverse families in South Africa. Cleft Palate-Craniofacial Journal, 43(1), 47-54.

Louw, H. (2007). Verskaffing en verspreiding van vroeë kommunikasie intervensie in die publieke gesondheidskonteks in geselekteerde provinsies in Suid-Afrika. Unpublished B. Communication Pathology research report, Department of Communication Pathology, University of Pretoria.

Madding, C.C. (2000). Maintaining focus on cultural competence in early intervention services to linguistically and culturally diverse families. Infant-Toddler Intervention. The Transdisciplinary Journal, 10(1), 9-18.

Maxwell, D.L., \& Satake, E. (2006). Research and statistical methods in communication disorders. London: Williams \& Wilkins.

National Health Act (2003). Retrieved on 8 June 2007 from http://www.info.gov.za/ speeches/2005/05042013451004.htm

Northern, J.L., \& Downs, M. (2002). Hearing in children (5th ed.). Baltimore: Lippincott, Williams \& Wilkins.

Pakendorf, C. (1998). 10 punt plan vir die vertaling en kulturele aanpassing van toetsmateriaal vir die SuidAfrikaanse konteks. Clinica: Applications in Clinical Practice in Communication Pathology, Monograph 3, 1-10.

Pepper, J., \& Weitzman, E. (2004). It takes two to talk. Toronto: Hanen Centre.

Popich, E. (2003). The development of a tool for communication stimulation for infants ( 0 - 12 months). Unpublished D.Phil. thesis, Faculty of Humanities, University of Pretoria.

Statistics South Africa (2003). Population Census Key Results. Retrieved on 8 June 2007 from http://www. statssa.gov.za/census01/html/Key\%20results_Key\%20results.pdf

Rossetti, L.M. (2001). Communication intervention: Birth to three (2nd ed). Albany: Singular Thomson Learning. Swanepoel, D. (2004). A review of the South African context: Information for community-based speech-language and hearing services. CLINICA: Applications in Clinical Practice of Communication speech-language and hearing se
Pathology, Monograph $9,11-16$.

Theunissen, M., \& Swanepoel, D. (2008). Early hearing detection and intervention services in the public health sector in South Africa. International Journal of Audiology, 47(1), 23-29.

Thompson, T. (1992). Developmental risk factors and poverty. In T. Thompson \& S.C. Hupp (Eds.). Saving children at risk: Poverty and disabilities. Newbury Park: Sage Publications.

Visser, C. (2005). Die toepaslikheid van 'n Afrikaanse vertaling van die 'Scan-C: Test for Auditory Processing Disorders in Children - Revised' vir voorskoolse leerders. Unpublished M. Communication Pathology dissertation, University of Pretoria.

Ziev, M.S.R. (1999). Earliest intervention: Speech-language pathology services in the neonatal intensive care unit. ASHA, May//une, 32-36. 